\title{
Mayo tries new model in clinical trial business
}

"The worlds of academia and market economics don't have to clash," Gary Lubin says. But he quickly adds that, in the field of clinical trials, he'll have to prove that in the face of conflicting evidence.

Lubin is chief executive officer of Centerphase Solutions, a company designed to help academic institutions efficiently conduct clinical trials in partnership with pharmaceutical companies. The company officially launched in January and is now in the early stages of planning three clinical trials with its first collaborator, the Mayo Clinic in Rochester, Minnesota.

Since the 1970s, pharmaceutical companies have attempted to cut drug development costs by outsourcing clinical trials to organizations called clinical research organizations (CROs). Amidst a worldwide economic recession, the practice is booming. The CRO market jumped from $\$ 15$ billion in 2007 to $\$ 20$ billion in 2008 - making it $29 \%$ of the $\$ 74$ billion global drug development budget, according to the industry analyst firm Centerwatch, which is not affiliated with Centerphase.

Whereas private CROs flourish, their academic counterparts, academic research organizations (AROs), struggle to find sound financial footing. The Mayo Clinic's first ARO, the Mayo Clinical Trial Services Unit, folded in November 2008.

Centerphase hopes to avoid that fate and to even expand to work with other academic centers. However, with a few notable exceptions, nearly all AROs have a history of struggling for profitability-largely because of added bureaucracy, says Ken Getz, a senior fellow at the Tufts Center for the Study of Drug Development.

Commercial CROs are responsible for simply collecting data in the most efficient way possible and then turning that data over to their clients. AROs must meet the standards held to academic institutions, which typically involve more review processes, the ability to publish data (whether it's positive or negative) and collaborations with agencies such as the US National Institutes of Health.

Additionally, AROs are typically confined to the patients served by that academic medical center. CROs hold trials wherever it is most cost efficient, which is why, according to Centerwatch, nearly half of clinical trials are currently conducted outside of the US in countries where costs and governmental oversight are reduced.

"CROs that have an international reach bring a lot of benefits to their clients in the pharmaceutical industry," says John Lewis,
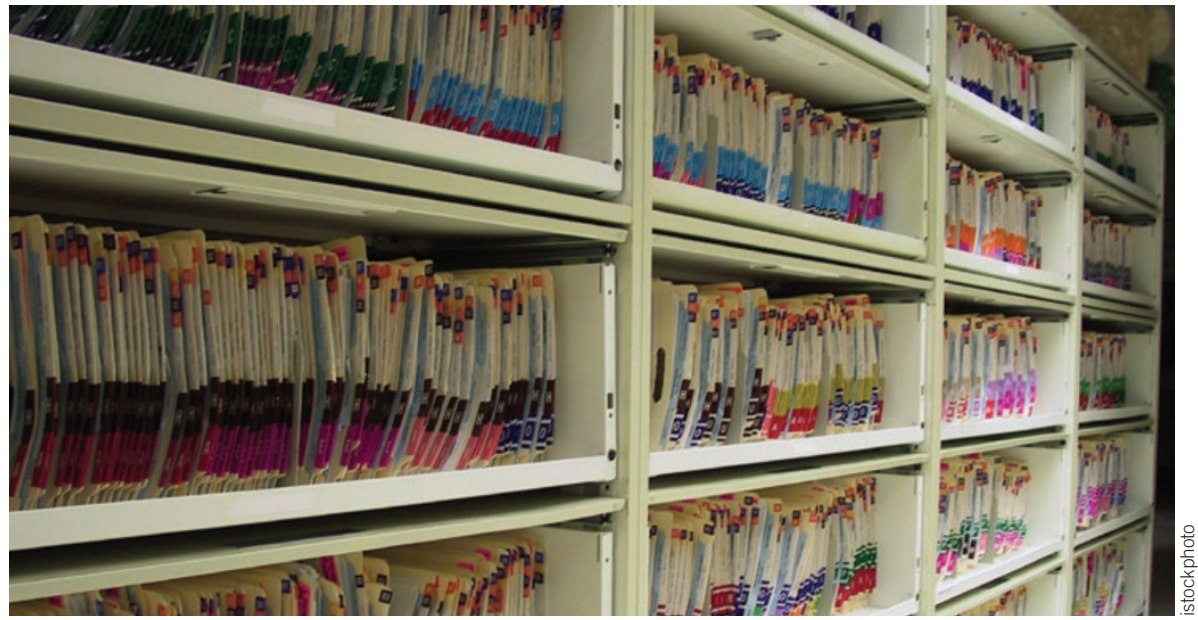

Data deluge: Academic medical centers hold a wealth of patient information. spokesperson for the Association of Clinical Research Organizations. "Sure, they can often enroll more patients in a more cost-effective manner in countries like India and Chinabut don't forget that these countries also represent huge potential future markets for these treatments. Most of our academic medical centers here haven't reached out there yet."

AROs that have been competitive, Getz says, have focused on an area of strong expertise. For example, Duke Clinical Research Institute in Durham, North Carolina, which many see as the most successful ARO, focuses on cardiology.

"In some ways, success is a question of the ARO quality versus private CRO quantity," Getz says.

Centerphase plans to specialize in gastroenterology, endocrinology, neurology, cardiology and oncology-areas of research strength for the Mayo Clinic. Mayo also houses the Enterprise Data Trust, a secure collection of data on more than 7 million patients, sometimes reaching back as far as 20 years.

That information, according to Lubin, will allow Centerphase to better tailor clinical trials to the known patient population. For example, when testing a drug for a particular condition, they would be able to estimate how many patients will be seen with that condition and thus determine what supplies are needed, how long the trial will take or even whether the trial should be held.

"We owe it to our patients to play a larger part in bringing new treatments," says Wayne Nicholson, who oversees the collaboration on behalf of the Mayo Clinic. "And we'll do that by using what has always been the academic institution's best tack-a more thoughtful approach."

Stu Hutson, Gainesville, Florida

\section{Myriad 'after-math'}

When a US federal judge rejected patents by Myriad Genetics on the BRCA1 and BRCA2 genes in late March, it put many in the biotech industry on edge after years of making similar claims of their own. Kyle Jensen, a director with the nonprofit PIPRA, has been tracking the patent push, and in 2005 he coauthored a study on human genome patenting (Science 310, 239-240, 2005). Below, Jensen provided Nature Medicine with updated data from 2009; of special note are more than 5,600 patents that claim rights to human DNA sequences. If these patents make specific claims similar to those rejected in the Myriad case, they, too, could be ruled invalid.

Christian Torres, New York

\begin{tabular}{|lll|}
\hline & 2005 & $\mathbf{2 0 0 9}$ \\
\hline Number of patents disclosing DNA sequences & 30,048 & 43,872 \\
Number of patents claiming DNA sequences & 18,970 & 23,838 \\
Number of patents claiming human DNA sequences & 4,270 & 5,657 \\
Percentage of human genes 'patented' & $20 \%$ & $30 \%$ \\
\hline
\end{tabular}

